\title{
Analysis of Welfare in Indonesia
}

\section{Basri Bado $^{1}$, Syamsu Alam², Vandy Eka Atmaja ${ }^{3}$, Saparuddin ${ }^{4}$}

\begin{abstract}
:
The purpose of this study is to analyze the factors of natural resources, income per capita, infrastructure, education, institutions and population against inequality between regions and welfare in Indonesia.

The study uses panel data regression analysis analyzing secondary data consisting of 33 provincial cross section data and 10 years time series data (2008-2017).

The results of the study found inequality between regions in Indonesia with different intensities. Factors of natural resources, income per capita, infrastructure, education, wealth and population have a positive and significant effect on inequality between regions.

Furthermore, $2 \%$ of the inequality variables between regions affect the level of welfare and the rest are influenced by natural resources, per capita income, infrastructure, education, institutions and population.
\end{abstract}

Keywords: Economic development, inequality, welfare, multi-regression.

\footnotetext{
${ }^{1}$ Lecturer at the Faculty of Economics, UNM, e-mail: basri.bado@unm.ac.id

${ }^{2}$ Lecturer at the Faculty of Economics, UNM, e-mail: alamyin@gmail.com

${ }^{3}$ Student at the Faculty of Economics, UNM, Development Economics Study Program

${ }^{4}$ Lecturer at the Faculty of Economics, UNJ, e-mail: itunk77@gmail.com
} 


\section{Introduction}

The endogenous growth theory explains that one of the inputs to economic growth is human. Schultz (2003) puts humans on a parallel way with physical capital such as machinery and technology. The theory explains that humans have an important role in the economy. Human capital emphasizes education, science, health and skills as capital that is very important for humans. Indicators for measuring human capital can be proxied by the Human Development Index (HDI).

Human Development Index (HDI) is a composite index that includes health index, education index, expenditure index. Romer (1992) states that human capital has a significant effect on economic growth. The concept of human capital is based on the orientation of productivity. Romer (1992) states that human capital is a fundamental source of economic productivity. This means that human capital is an investment that can increase productivity. Even recently Zaman (2012) defines that human capital as a combination of various factors, namely education, experience, training, intelligence, work habits, integrity, and initiatives that can have an impact on the marginal productivity of labor.

Economic growth and human capital has a two-way relationship. First, economic growth towards human capital, namely economic growth will affect human development, especially through the activities of society and government. HDI by the United Nation Development Program (UNDP) is also used as an indicator of welfare.

Based on data (BPS, 2018) the level of the welfare measured by the Human Development Index has an increasing trend. This condition indicates that the level of welfare nationally has improved, but at the same time we often find social reality in the community that does not reflect welfare itself. There are still some people who are not touched by education and health, not to mention regional problems that are progressing so rapidly but on the other hand there are areas that are still lagging behind, thus triggering social jealousy, tension, and triggering inequality. In the 2011-2017 period, Indonesia in general experienced improved welfare, but the above phenomena indicated that not all levels of society felt prosperity, or in other words, there was inequality in the society. The stigma of eastern Indonesia and western Indonesia clarifies the products of inequality itself, should all levels of the society to enjoy the results of development as a form of implementation of the value of social justice.

Seven out of 34 provinces in Indonesia have high HDI values. In general, the average HDI scores of the seven provinces are above the average national achievement score. The highest achievement of HDI is DKI Jakarta, which in fact is the capital of the country. As a province with a high average HDI score in Indonesia, in the 2011-2017 period of course the province has a good economic performance. 
Broadly speaking, the process of economic development is influenced by how economic and non-economic factors in a region work (Jhingan 1994).

Myrdal's theory of long-term inequality is considered a necessary condition to improve the living standard of the population through a trickledown effect, but Todaro (2000) found that there was not always a trickle-down effect that occurred on the contrary, the trickle up effect or the results of development flow more to the more affluent groups compared to the average population. As a country with a diversity of backgrounds, making Indonesia cannot be separated from the problem of inequality. This condition is evidenced by the Indonesian Gini index value in 2015 which reached 0.41 , which means that Indonesia experienced a moderate level of inequality. It is not surprising that the problem of inequality occurs in Indonesia, given that inequality is a problem faced by many developing countries.

Inequality in developing countries has direct implications for welfare. Todaro (2000) suggests that inequality has a negative effect on well-being. Thus, the problem of inequality and well-being becomes something so complex and complicated

\section{Theoritical Review}

Todaro (2011) suggests that measuring the level of welfare of a country can be used as a parameter of the Human Development Index. One of the advantages of HDI is that this index reveals that a country / region can do much better at a low-income level, and that a large increase in income only plays a relatively small role in human development. The general formula used to calculate the Human Development Index is as follows:

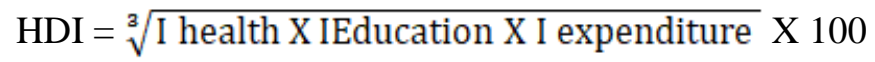

Each of these components is first calculated so that the value is between 0 (worst) and 1 (best). Sjafrizal (2014) claimed that the causes of economic inequality between regions are:

1) Differences in the content of natural resources;

2) Differences in geographical conditions;

3) Less smooth mobility of goods and services;

4) Concentration of economic activities;

5) Allocation of development funds between regions.

The theory that explains about inequality is as follows, including the Lorenz Curve which describes the relationship between population groups and their share (share) of income. 
Figure 1: Lorenz curve

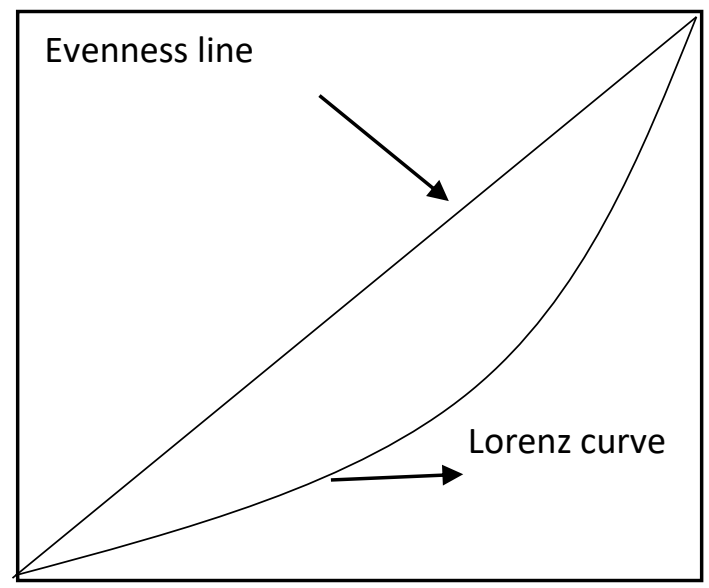

The Lorenz curve shows the cumulative relationship between the percentage of the population and the percentage of income they receive. The further the Lorenz curve from the diagonal line (perfect evenness), the higher the degree of inequality shown. The most extreme conditions of inequality are perfect, for example situations where all income is only received by one person, will be indicated by the intersection of the Lorenz corva with the lower horizontal axis and the right vertical source (Todaro 2011).

Myrdal's theory of inequality emphasizes the divergent process that causes inequality to widen. This phenomenon is explained by Myrdal as a result of accumulative causation (CC). Myrdal (1957) in Jhingan (1994) mentions the existence of adverse effects (backwash effects) to explain the phenomenon of increasing inequality between developed and developing countries. Myrdal believes that the backwash effect is greater than the spread effect. The impact of the spread is the impact of expansion in the center of economic activities to areas that are relatively left behind through increasing demand for agricultural products (such as food), raw materials, and consumer goods produced by small industries. This is the least happening in Indonesia because:

1) there are still many agricultural and industrial products imported from abroad;

2) weak linkages between large and small businesses in Indonesia.

\section{Methodology}

Population is a generalization area consisting of objects or subjects that have certain qualities and characteristics set by the researcher to be studied and then conclusions drawn. The population in this study is the Gini Index, Primary GDP, per capita income, electricity distribution, average school length Indonesia's democracy index, population and HDI in Indonesia. Whereas, the sample is part of the number and 
characteristics possessed by the population. The samples in this study is the Gini Index, primary GRDP, electricity distribution, per capita income, average length of school, Indonesian democracy index, population and HDI in Indonesia in the period 2011-2017.

Data analysis technique:

1. Inequality Analysis: Indicators of inequality use the Gini Index, following the Gini Index equation:

$$
\left.\mathrm{GR}=1-\sum_{\mathrm{i}=1}^{N} \text { fpi } X \mathrm{Fci}+\mathrm{Fci}-1\right)
$$

where:

GR: Gini Coefficient

Fpi: Frequency of population in the i class of expenditure

Fci: Cumulative frequency of total expenditure in the i class expenditure

Fci-1: Frequency of total total expiry in the expenditure class to (i-1)

The Gini index ranges from 0 to 1 . If the Gini coefficient is 0 , it means perfect equalization and if the Gini coefficient is 1 , it means perfect inequality (Table 1).

Table 1. Gini values

\begin{tabular}{|l|l|}
\hline Gini & Distribution \\
\hline$<0,4$ & Low Level \\
$0,4<0,5$ & Level of Moderate \\
$>0,5$ & High Level \\
\hline
\end{tabular}

2. Regression Analysis: This study uses panel data regression analysis to analyze economic, social and demographic factors that influence inequality between regions in Indonesia. Data with panel characteristics are data that are structured sequentially at the same time cross section at a certain period (Ariefianto, 2012). With the basic equation of pooled data regression are as follows:

3.

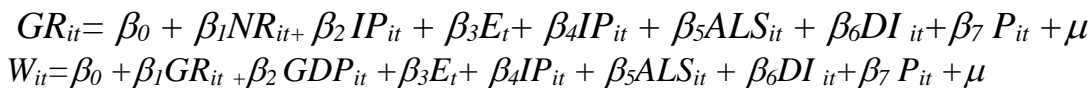

GR = Gini Ratio

$\mathrm{W}=$ Welfare

$\mathrm{NR}=$ Natural Resources

$\beta 0=$ Intercept $/$ constant

$\beta 1, \beta 2, \beta 3=$ The independent variable regression coefficient

LnGDP $=$ Primary GDP

LnE=Electricity

$\mathrm{LnIP}=$ Per capita income

$\mathrm{ALS}=$ Average length of school 
$\mathrm{DI}=$ Democracy Index

LnP=Population

$\mu=$ disturbance error

\section{Results and Discussion}

\subsection{GR Model}

Analysis of the influence of natural resources, per capita income, infrastructure, education, institutions, and population numbers on inequality uses panel data regression analysis with fixed effect specifications. The estimated results of the pooled data regression model are as follows (Table 2):

Table 2. Results of the GR Model Estimation

\begin{tabular}{lllll}
\hline Independent Variabel & Theory & coefficient & $\mathrm{t}_{\text {-stat }}$ & Sig. \\
\hline $\mathrm{NR}$ & + & $8.12^{*}$ & 1.85 & 0.0652 \\
$\mathrm{IP}$ & + & $-7.32^{\mathrm{ns}}$ & -0.94 & 0.3470 \\
$\mathrm{E}$ & + & $1.91^{\mathrm{ns}}$ & 0.80 & 0.4206 \\
$\mathrm{ALS}$ & + & $0.004^{\mathrm{ns}}$ & 0.57 & 0.5637 \\
$\mathrm{DI}$ & + & $-6.39^{\mathrm{ns}}$ & -0.24 & 0.8035 \\
Population & + & $-7.58^{\mathrm{ns}}$ & -0.88 & 0.3799 \\
\hline Intersep & & & & 0.366946 \\
\hline Adjusted $\mathrm{R}^{2}$ & & & & 0.79 \\
\hline $\mathrm{F}$ Stat & & & 17.96 \\
\hline $\mathrm{DW}$ & & & & 165 \\
\hline $\mathrm{N}$ & & & & \\
\hline
\end{tabular}

Note: *: Significant at an error rate of $10 \%(0.1)$ or $90 \%$ confidence.

Ns: Non-significant.

Based on the results of the regression analysis used, the equations are as follows:

$$
\begin{aligned}
& G R=0.36+8.12 N R_{i t}-7.32 I P_{i t}+1.91 E_{i t}+0.004 A L S_{i t}-6.39 I D_{i t} \quad- \\
& 7.58 \text { Pop }_{i t}+\mu_{i t}
\end{aligned}
$$

GR between regions in Indonesia is a true phenomenon that occurs as the problem faced by other developing countries. This imbalance is a trade off from the development process that is temporarily carried out. This condition is in line with the findings of Kuznet (1995) which states that the development process at certain boundaries will create a gap between its citizens which is then known as the Kuznet hypothesis.

From the results of panel data regression using Eviews 10 software, GDP simultaneously had a positive and significant effect on inequality with a $10 \%$ fatigue 
rate. Regression coefficient of 8.12 , meaning that if there is an increase in Primary GDP by $1 \%$ it will increase inequality between regions by $8.12 \%$.

The findings are in accordance with the research hypothesis. The role of primary GRDP, which is still quite dominant towards the formation of GDP in Indonesia, is thought to be the cause of conditions in which if there is an increase in primary GRDP it will increase inequality. These results can be observed that primary GRDP throughout 2011-2017 contributed 25\% to GDP formation, with details of the Agriculture sector at $14 \%$ and mining $11 \%$. This condition explains that the agriculture and mining sectors are one of the biggest contributors to GDP formation. The role of the primary sector which is quite dominant towards the formation of GDP reflects Indonesia's natural wealth, but it should be noted that not all regions have the same natural wealth.

Indonesia is famous for the term agrarian country, or most of its population searches in agriculture, this condition is supported by the contribution of agriculture to GDP which reached $14 \%$. Although the role of agriculture is quite dominant, the condition is very worrying when comparing the percentage of the number of people working and the percentage of income in agriculture. In line with the agricultural sector, the mining and quarrying sector is also quite dominant towards GDP formation.

Although the mining and quarrying sector is a capital-intensive sector or does not absorb much labor, mining has high added value. The development of the primary sector in almost all provinces during the study period experienced an increasing trend with different intensities. This condition has been explained in Table 2, meaning that the increase in the primary sector with different intensities causes the primary sector to have a positive effect on inequality between regions. The results were found to be relevant to the study (Yeniwati 2013) which found that natural resources had a significant effect on economic inequality between provinces in Sumatra.

\subsection{The Welfare Model}

Analysis of inequality to welfare uses panel data regression analysis with the model random effect specification. Gujarati and Porter (2009) suggest that the equation that meets the classical assumptions is only the equation that uses the Generalized Least Square (GLS) method. In Eviews the random effect estimation model uses GLS so that the model of inequality research on welfare does not need to be tested on classical assumptions. The estimated results of the panel data regression model are as follows (Table 3):

Table 3. Results of the Welfare Model Estimation

\begin{tabular}{lllcc}
\hline Independent Variable & Theory & Coefficient & t stat & Sig. \\
\hline GR & - & $18,52^{* *}$ & 2,14 & 0,0336
\end{tabular}




\begin{tabular}{ll}
\hline Intersep & 60,50 \\
\hline Adjusted $\mathrm{R}^{2}$ & 0,02 \\
\hline $\mathrm{N}$ & 165 \\
\hline
\end{tabular}

Note: **: Significant at an error rate of 5\% (0.05) or 95\% confidence.

T.H: A sign of hope.

Based on the results of the regression analysis used, the equations are as follows:

$\mathrm{HDI}=60.5+18.52 * *$ GR it $+\mu \mathrm{i}$

The results showed that the Gini index variable partially and simulatively had a significant effect on HDI. The regression coefficient of 18.52 showing that the Gini index has a positive effect on welfare in Indonesia. This value means that if inequality between regions increases by $1 \%$, it will increase the HDI by $18.5 \%$

The results of the study are positive and significant according to the research hypothesis, where inequality between regions has a positive and significant effect on well-being. This condition is in line with the opinion of Kuznet (Arsyad 2010) which states that inequality is a condition that must be sacrificed in the development process to achieve prosperity. Improvement of variables in research such as natural resources, income per capita, infrastructure, education, institutions and population influence economic growth in an effort to achieve prosperity but in the process the problem of inequality is a trade off for prosperity.

In the estimation model of inequality, it was found that there was an increase in the intensity of inequality between regions due to different economic performance between regions. Improved performance is supported by improvements in the variables of natural resources, income per capita, infrastructure, education, institutions and population. Aside from being an input in the development process, the United National Development Program (UNDP) stipulates HDI as an indicator of welfare. Based on Table 3, it can be said that the level of welfare in the regional area has increased.

The findings explain that increasing welfare is also accompanied by an increase in the intensity of inequality between regions. This condition is in line with the opinion of Kuznet in Arsyad (2010), (Basri Bado and Salamun 2015) which states that in the development process to achieve prosperity at certain limits will create a gap between its citizens. Increasing the level of well-being in Indonesia, along with the improvement of independent variables in research, is also supported by improvements in basic services such as education, health, public works and spatial planning, public housing and residential areas, peace, public order, public and social protection. 


\section{Conclusion}

Based on the analysis that has been done, some conclusions can be obtained as follows:

1. Inequality occurs between regions in Indonesia with different intensities. Seven provinces experienced inequality with moderate categories and 27 others experienced inequality with low categories. In addition, it was found that the intensity of inequality in urban areas was greater than inequality in rural areas.

2. Differences in primary GDP variables, per capita income, infrastructure, education, institutions and population affect economic performance which has an impact on differences in economic growth outcomes. The difference in achievement of economic growth experienced by the regions will cause a gap, this gap is then called inequality between regions in Indonesia.

3. Inequality between regions has a significant effect on the level of welfare in Indonesia. The increase in welfare in the regional arena is also accompanied by an increase in inequality between regions, a condition that is reasonable because inequality is a trade off that must be sacrificed in the development process of developing countries.

\section{References:}

Adisasmita, R. 2013. Theories of Economic Development. Yogyakarta, Graha Ilmu.

Arsyad, L. 2010. Economic Development. Jakarta, UPP STIM YKPN.

Basri Bado and Salamun, P.A.S., Rijal. 2015. Analysis of the Influence of Average Length of School and Education Level of Workers Against Poverty South Sulawesi.

International Journal of Applied Business and Economic Research, 13(2), 551-559.

Basri Bado and Wardihan, S. 2014. Priority Sector of Economic Development. Journal of Development and Agriculture Economics, 6(1), 380-386.

BPS. 2018

Faisal, S.Q., F.A.D.A.W., Waheed. 2011. Human Capital and Economic Growth: Time Series Evidence from Pakistan. MPRA, 30654, Http://Mpra.Ub.UniMuenchen.De/30654/

Jhingan, M.L. 1994. Development Economics and Planning. Jakarta, Rajawali Press.

Kuncoro, M. 2010. Problems, Policies and Politics of Economic Development. Jakarta, Airlangga.

Romer, D. 1992. A Contribution to the Empirical of Economic Growth. The Quarterly Journal of Economics, Harvard College and the Massachusetts Institute of Technology.

Romer, D. 1990. Endogenous Technological Change. Journal of Political Economy, 98, 71102.

Schultz, T.P. 2003. Human Capital. Schooling and Health Returns.

Sjafrizal. 2014. Regional and Urban Economics. Jakarta, Rajawali Press.

Todaro, M.P. 2000. Economic Development (7th Edition). New York, Addison-Wasley, Logman, Inc.

Todaro, M.P. 2011. Economic Development in the Third World. Jakarta, Erlangga.

Umiyati, E. 2013. Analysis of Economic Growth and Inter-Regional Development Inequality 
on the Island of Sumatra. Journal of Economic Paradigm, 1(7).

Yanling Li, A.A. 2011. An Empirical Research on Influential Factors in Poverty of Peasant Households in Minority Regions in China. Journal of Agricultural Science, 3(1), 218-227.

Yeniwati. 2013. Inter-Provincial Economic Inequality in Sumatra. Journal of Economic Studies, 2(3), 1-2.

Zaman, M. 2012. Human Capital and Economic Growth: An Empirical Investigation Using Panel Data. IOSR Journal of Humanities and Social Science, 4(6), 43-56. 